\title{
Clinical Case: Earlobe Keloid
}

\section{Luc Téot}

\section{Contents}

\subsection{Medical History - 524}

Further Readings - 526 


\subsection{Medical History}

A 23-year-old Asian-origin young male came after a long period of keloid of the left ear, secondary to a minor trauma during childhood. The patient was treated by three sequential surgical excisions followed by a recurrence, the last one being followed by YAG laser.

The patient abandoned the possibility to be adequately treated by any therapy during 7 years and was examined at the clinic (• Figs. 61.1 and 61.2).

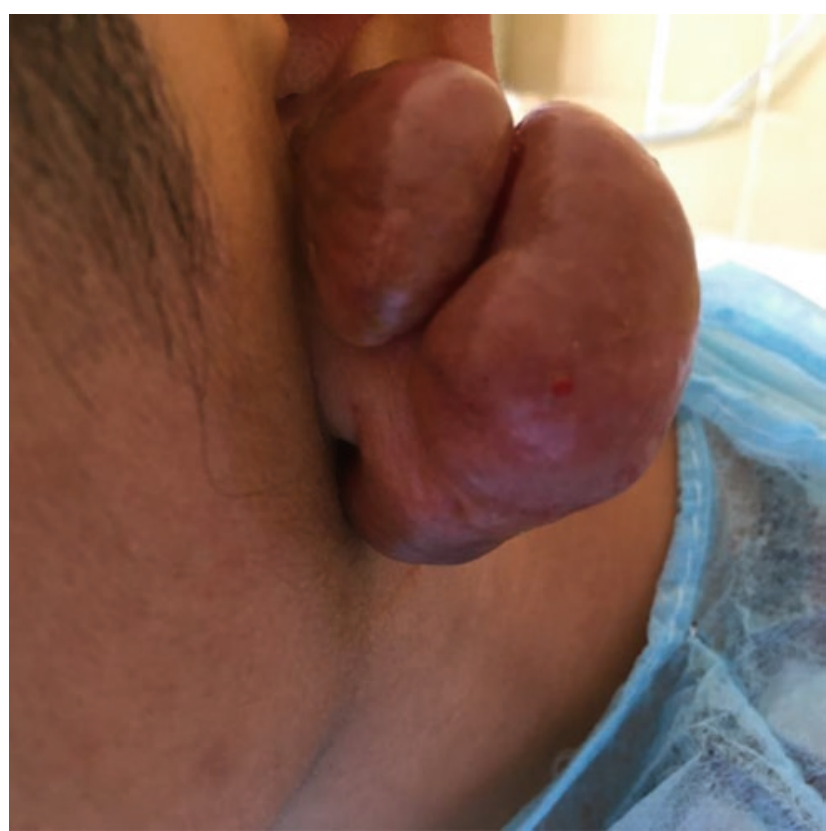

- Fig. 61.1 Earlobe keloid at presentation (anterior view)

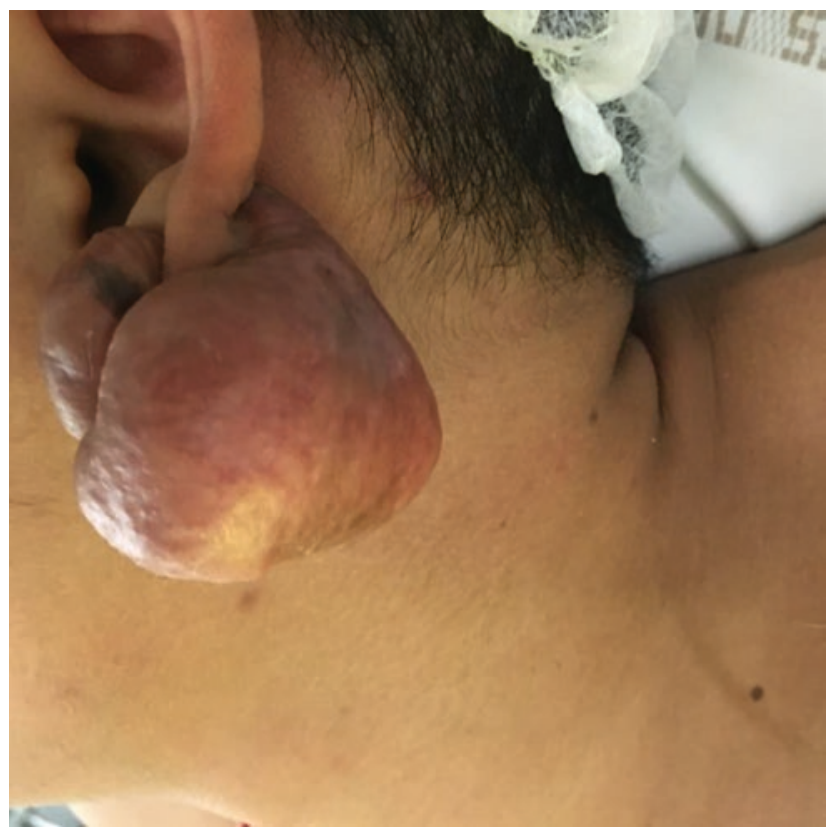

- Fig. 61.2 Earlobe keloid at presentation (posterior view)
Questions to Medical History

- Is Asian origin a predetermining factor for earlobe keloid?

- Is keloid growing permanently or does it stop with age?

- Is there any guideline for surgical management of keloid?

\section{- - Intervention 1}

A series of 105 -FU injections $(5 \mathrm{~mL})$ at a dosage of $50 \mathrm{mg} / \mathrm{mL}$ was administered at 3 weeks of interval.

The procedure was standardized as follows:

- EMLA cream application 2 hours before injection

- MEOPA (hilarant gas able to disconnect the patient from pain) administration during injection

- Hypnose adjuvant therapy during injection (hypnose works to deviate the attention of the patient and present a growing interest particularly on patients submitted repeatedly to painful stimulation) (• Figs. 61.3 and 61.4)

\section{Questions: Procedure 1}

- Why 5-FU injections instead of corticosteroid injection?

- What is the rationale of the dose $(50 \mathrm{mg} / \mathrm{mL})$ ?

- How painful is the procedure?

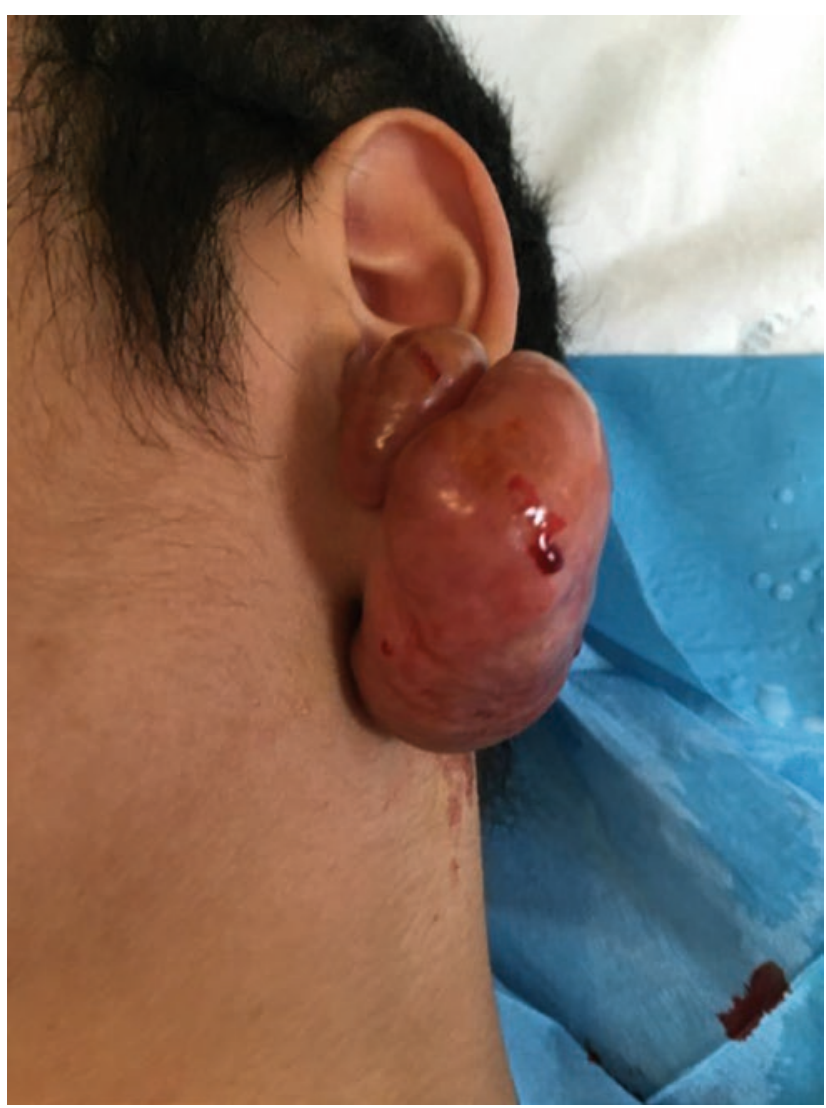

- Fig. 61.3 Inflammatory aspect during 5-FU injections (anterior view) 


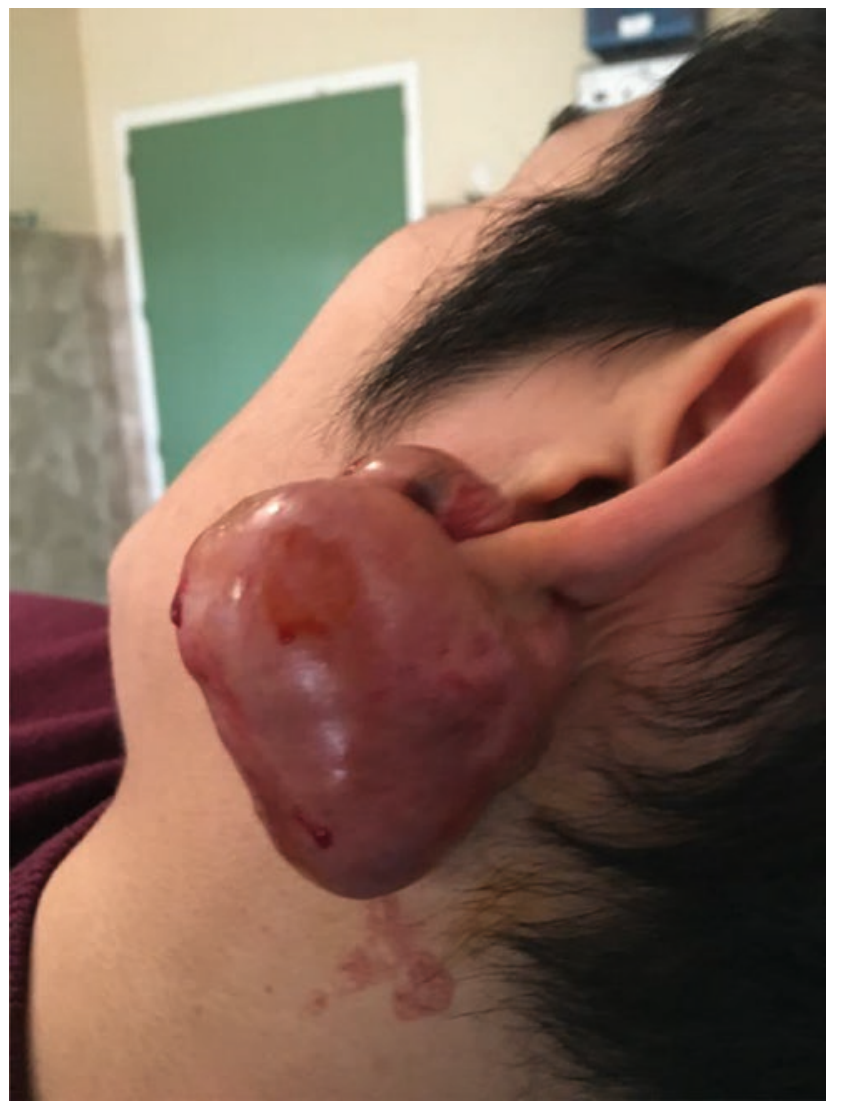

- Fig. 61.4 Inflammatory aspect during 5-FU injections (posterior view)

\section{- Intervention 2}

A surgical excision was administered with reconstruction of the earlobe with a combined approach anteriorly and posteriorly to the earlobe. A compression was made at fashion to ensure the mechanical situation during the 12 months postoperative period. The results were good with no recurrence. The scar presented redness after 3 months postoperation and then this inflammation was resolutive with time (• Figs. 61.5 and 61.6).

\section{Late Postintervention Questions}

- Why to choose not to apply any postoperative therapy?

- What about the loss of substance of the ear?

- Is there a need for complementary surgery?

- Is further surgery contraindicated?

\section{$\checkmark$ Answers}

The prevalence of earlobe keloid is higher in the Asian skin than in the Caucasian skin even if the global risk of keloid is higher in the black-skin population. Keloids are, contrary to hypertrophic scars, growing permanently, reaching enormous sizes when left apart without adapted treatment.

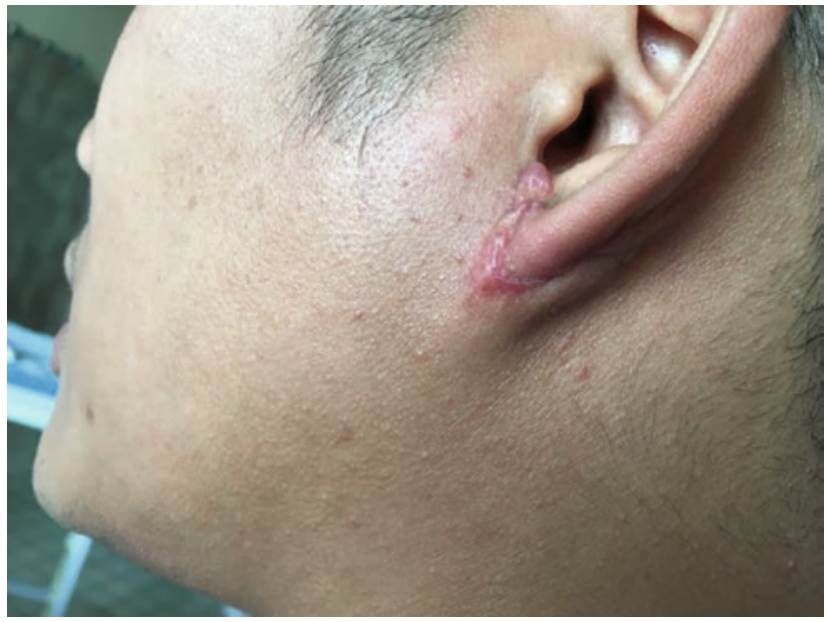

- Fig. 61.5 Aspect of the ear 3 months postopertion, and some inflammation is still present

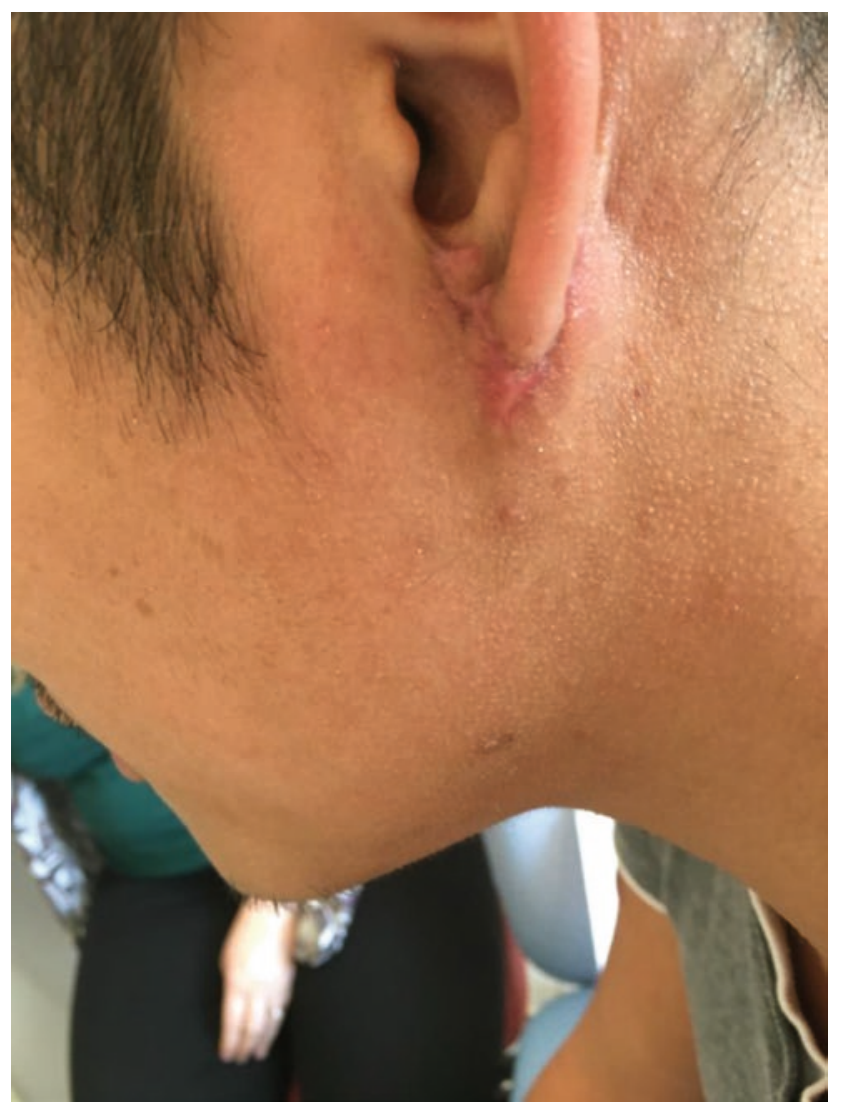

- Fig. 61.6 Aspect at 14 months postoperation: the scar is stable and no recurrence occurred

Guidelines of surgical scar management mention the need for a combination of techniques, and most of them are being proposed after surgery (radiotherapy, cryotherapy, laser). Cryotherapy has also been proposed as an alternative to surgery. In this case the preoperative management using antimitotic agents 
was proposed to limit the fibroblast postoperative proliferation 5 -FU is used at a high dose $(50 \mathrm{mg} / \mathrm{mL})$ as suggested by several authors without systemic complications and the rhythm of injections (every 3 weeks) limits the risk of local skin necrosis.

This strategy limits the risk of recurrence after surgery and is proposed as a new option, in combination with preoperative injections and a close checkup of the local situation during 1 year.

The major inconvenience is pain induced by the injection, and pain management needs combined therapies (EMLA, MEOPA, Hypnose). During the surgical procedure the loss of substance of the earlobe had to be treated by reapproximation of the edges, a source of limited cosmetic difference compared to the contralateral side, but the patient refused to be reoperated, considering the high risk of worsening of the scar and of recurrence of the keloid.

\section{Further Readings}

Ragoowansi R, Cornes PG, Glees JP, Powell BW, Moss AL. Earlobe keloids: treatment by a protocol of surgical excision and immediate postoperative adjuvant radiotherapy. Br J Plast Surg. 2001;54(6):504-8.

Park TH, Cho HJ, Lee JW, Kim CW, Chong Y, Chang CH, Park KS. Could $-79^{\circ} \mathrm{C}$ spray-type cryotherapy be an effective monotherapy for the treatment of keloid? Int J Mol Sci. 2017;18(12). pii: E2536. https://doi.org/10.3390/ijms18122536.

Carvalhaes SM, Petroianu A, Ferreira MA, de Barros VM, Lopes RV. Assessment of the treatment of earlobe keloids with triamcinolone injections, surgical resection, and local pressure. Rev Col Bras Cir. 2015;42(1):9-13. https://doi.org/10.1590/010069912015001003.

Waibel JS, Wulkan AJ, Rudnick A, Daoud A. Treatment of hypertrophic scars using laser-assisted corticosteroid versus laserassisted 5-fluorouracil delivery. Dermatol Surg. 2018; https://doi. org/10.1097/DSS.0000000000001678.

Kumar K, Kapoor BS, Rai P, Shukla HS. In-situ irradiation of keloid scars with Nd:YAG laser. J Wound Care. 2000;9(5):213-5.

\section{Take Home Message}

This clinical case reports the interest of a combined strategy using sequential intralesional chemotherapy before surgery in order to limit the rebund effect in highly proliferative ear keloids.

Open Access This chapter is licensed under the terms of the Creative Commons Attribution 4.0 International License (http://creativecommons. org/licenses/by/4.0/), which permits use, sharing, adaptation, distribution and reproduction in any medium or format, as long as you give appropriate credit to the original author(s) and the source, provide a link to the Creative Commons license and indicate if changes were made.

The images or other third party material in this chapter are included in the chapter's Creative Commons license, unless indicated otherwise in a credit line to the material. If material is not included in the chapter's Creative Commons license and your intended use is not permitted by statutory regulation or exceeds the permitted use, you will need to obtain permission directly from the copyright holder.

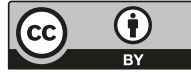

